\title{
Age stratified Seroprevalence of Cytomegalo virus in children
}

\author{
Kamalammal $\mathbf{R}^{1}$, Balaji ${ }^{2}$, Mohamed Sait $\mathbf{Y}^{3}$ \\ ${ }^{1}$ Dr Rugmini Kamalammal, Associate Professor, Department of Paediatrics, Adichunchanagiri Institute of Medical \\ Sciences, B G Nagara, Mandya District, Karnataka, India, ${ }^{2}$ Dr Balaji, Associate Professor, Department of Paediatrics, \\ Adichunchanagiri Institute of Medical Sciences, B G Nagara, Mandya District-571448, Karnataka, India, ${ }^{3}$ Dr Mohamed \\ Yaseen Sait, Registrar, Mehta Childrens Hospital, Chennai, Tamilnadu, India.
}

Address for correspondence: Dr Rugmini Kamalammal, Email: rugminirao@yahoo.com

\begin{abstract}
Introduction: Cytomegalovirus seroprevalance in developing countries is found to be high but there is no recent study done in India especially in children. Primary CMV infection is asymptomatic, but the virus remains latent in organs and children shed the virus in their urine and saliva for a long period. Primary infection can cause major consequences in growing fetus, premature infants, and immune deficient individuals especially those with AIDS. It highlights the need for sero negative blood for transfusion. Methods: This cross sectional study done in children of the age group 0 to 18 years, serum samples were collected randomly from the children and neonates were used for IgG anti-CMV antibody titration by ELISA kit. Data were analyzed by SPSS, Windows version 15. Chi-squar tests were applied. Result: The overall prevalence was $84 \%$. The prevalence in age groups 1-28 days, 28 days to 1 year, 1-5, 6-10, 11-15, 16-18 years were $92.8 \%, 87.5 \%, 86.2 \%, 85 \%, 69.2 \%, 100 \%$ respectively. There was no statistically significant association between CMV sero prevalence and age, gender, residential area. Conclusions: Study shows a high prevalence of CMV infection in the age group especially chance of acquiring the infection drastically increases in the 1-5 years and 5-10 years population. High prevalence in neonates but relatively low prevalence in infants suggests maternal transmission rather than intrauterine infection. It is prudent to provide CMV screened blood products especially for preterms, immune deficient individuals.
\end{abstract}

Key words: Cytomegalovirus, Seroprevalence, ELISA, Children.

\section{Introduction}

Cytomegalovirus infection is one of the most prevalent infections in the developing world but the impact of this virus on our population goes unnoticed as the infection is usually asymptomatic. Morbidity occurs during late period of infection and not in intial viremic phase and the impact on health of the individual is mainly evident after years as hearing deficit and ocular problems. It is reported that $0.7 \%$ of U.S. infants are born with congenital CMV infection [1]. In infancy, CMV infection generally results from mother-to-infant transmission through genital secretions during birth or postnatally via breast milk [2]. Infants and young children acquire CMV infection via close contact with young children in household or day care settings $[3,4]$. The transmission is by direct or indirect contact with secretions of the infected people. After primary CMV

Manuscript received: $25^{\text {th }}$ April 2016

Reviewed: $6^{\text {th }}$ May 2016

Author Corrected; $17^{\text {th }}$ May 2016

Accepted for Publication: $29^{\text {th }}$ May 2016 infection the virus remains latent in many organs including kidney, lung, gastrointestinal tract and genitourinary system and the reactivation of the infection poses a significant challenge in this era of transplantation. T-cell immune deficient individuals mainly fetuses, premature infants, transplant recipients, and HIV patients are at high risk for acquiring serious CMV diseases. There is a lack of facilities for leukocyte depleted blood products for the multi-transfused patients with hematological diseases.

A study in healthy U.S. children during $1980 \mathrm{~s}$ was $17 \%$ [3]. CMV seroprevalence among children 6 to 11 years old was 38\% overall during 1999 to 2004 [5]. Cytomegalovirus (CMV) seroprevalence among U.S. children 1 to 5 years old was assessed in the National Health and Nutrition Examination Survey of 2011 to 2012. The overall seroprevalence ( $95 \%$ confidence interval) of IgG was $20.7 \%$ (14.4 to $28.2 \%$ ), that of $\operatorname{IgM}$ 
was $1.1 \%$ (0.4 to $2.4 \%$ ), and that of low IgG avidity was $3.6 \%$ (1.7 to $6.6 \%$ ), corresponding to a $17.3 \%$ (10.1 to $26.7 \%$ ) prevalence of recent infection among IgGpositive children [6].

Congenital cytomegalovirus (CMV) infection is asymptomatic in $90 \%$ of infected newborns but approximately $10-20 \%$ of these infants are at risk of developing sequelae later, mostly hearing deficit.The risk of hearing loss is greatly increased (about 20times) in CMV infected infants [6]. The virus remains latent in the young individuals for years and gets reactivated.

The incidence of CMV disease during the first year after HSCT is $8 \%$ but it is still a common complication in HSCT recipients especially those who are on Steroid therapy. GVHD and lack of CMV-specific T cells posttransplant are major risk factors for $\mathrm{CMV}$ reactivation [7]. CMV infections result from primary infection or reactivation, and most cases occur between 6 and 12 weeks after transplant [8, 9]. In a study. CMV reactivation occurred in median duration of 52.5 days (range 35-178 days) post transplant [6].

Sensitive test for CMV is Quantitative real-time polymerase chain reaction (qPCR) assay for CMVDNA $[9,10]$. Shedding of CMV virus in young children is diagnosed by performing viral culture on urine or saliva. In a study it was found that 9 of $13 \mathrm{CMV}$ seropositive children [69\%] were shedding virus in one or more bodily fluid [11].

Seroprevalance in India is very high with about $95 \%$ of the healthy blood donors in India being CMV seropositive [12,13]. In developing countries most children acquire the infection before reaching the age of three years and almost all persons have been infected before adulthood. In contrast in developed countries many of the population are seronegative prior to adolescent ages. Most studies in India is done among adults, especially volunteer blood donors, women, pregnant women. The purpose of this study was to investigate the age-stratified seroprevalence of CMV infection in children.

\section{Methods}

This was a cross sectional study done in 100 healthy children of the age group new born to 18 years, serum samples were collected randomly from the children attending hospital outpatient department and also newborns born in a teaching hospital in South India were used .Written informed consent was obtained from the caretakers and the research was approved by bioethics committee of the institution. Frozen samples were liquefied in room temperature and examined for IgG anti-CMV antibody witha commercial enzymelinked immunosorbent assay (ELISA) kit (EuroimmunLabeck). In accordance to the protocol of the kit absorbance values less than 16 reported negative, 16-22 borderline, and more than 22 positive. The serums with borderline absorbance was reexamined and accordingly reported as negative or positive. The data analysis was performed with the Statistical Package for Social Sciences SPSS for Windows. Chi- square tests were used to examine seroprevalence in different age, sex, socioeconomic status, residency in the studied people. A P-value of less than 0.05 was considered significant.

\section{Results}

Out of 100 serum samples examined, results of 84 cases were positive, 15 were negative and one sample was borderline. On re-examination of this sample, the result was negative. The prevalence of the CMV infection in the age group of 0-16 years was $84 \%$. The number of participants in the study was only 100 but this is considered to be satisfactory as various previous studies in different parts of the world has given a prevalence rate of over $84 \%$. The seroprevalence of CMV infection in various age groups has been represented in Table-I.

Table-1: Age wise prevalence of CMV IgG positivity in Children.

\begin{tabular}{|c|c|c|c|c|}
\hline Age group & Number & CMV Positive & CMV Negative & Percentage \\
\hline 0-28 days & 28 & 26 & 2 & 92.8 \\
\hline 29 days to 1 year & 8 & 7 & 1 & 87.5 \\
\hline 1-5 years & 29 & 25 & 4 & 86.2 \\
\hline 6-10 years & 20 & 17 & 3 & 85 \\
\hline 11-15 years & 13 & 9 & 4 & 100 \\
\hline 15-16years & 2 & 2 & - & \\
\hline
\end{tabular}


Among the study group $50 \%$ were male. Statistical analysis revealed no statistically significant difference in CMV prevalence between male and female the percentage of positivity being $86 \%$ in male and $82 \%$ among females (P-value 0.298). According to residence $26 \%$ were from rural background and the $74 \%$ were urban. Analysis according to place of residence also showed no significance positivity being $80 \%$ in urban and $83 \%$ in rural set up. (P-value 0.392)

There was an increase in prevalence rate of CMV from 1month to 15 years. The prevalence showed varying statistically significant difference on comparing each age group.

Table-2: showing comparison of CMV positivity between different age groups.

\begin{tabular}{|c|c|c|c|}
\hline Age group & $\begin{array}{c}\text { Percentage of CMV } \\
\text { positivity }\end{array}$ & $\begin{array}{c}\text { Percentage of CMV } \\
\text { negativity }\end{array}$ & P value \\
\hline 29 days to 1 year & 87.5 & 12.5 & \multirow[t]{2}{*}{$0.007 *$} \\
\hline $1-5$ years & 86.2 & 15.8 & \\
\hline $1-5$ years & 86.2 & 15.8 & \multirow[t]{2}{*}{$0.014 *$} \\
\hline 6-10 years & 85 & 16 & \\
\hline $6-10$ years & 85 & 16 & \multirow[t]{2}{*}{1.172} \\
\hline 11-15 years & 69.2 & 30.8 & \\
\hline
\end{tabular}

$* \mathrm{P}$-value $<0.05$ is significant

On analysis the age group of 1-5 years to find whether the exposure to peer group is a major factor in acquiring CMV infection by comparing those who are going to school with those who are not going, but this also did not give a significant difference

\section{Discussion}

In this study, the overall prevalence rate in age group 016 years was $84 \%$ which is in agreement with previous studies. In a study done, in Iran the overall prevalence in population was $98.2 \%$. The prevalence in age groups of 6-9, 10-19 were 95.7, 98.6 percent respectively. There was no statistical significant association between CMV seroprevalence with age, gender, education, family member, and residency groups in this previous study [14]. In another study in Iran itself the reported CMV prevalence in age groups of less than 1, 1-5, and higher than 5 years old were $73.9 \%, 73.9 \%$, and $97 \%$ respectively [15]. The overall prevalence of CMV antibody was $64.2 \%$, increasing from $54.4 \%$ in $4-6$ year-olds to $73.3 \%$ in subjects $17-18$ years old in a study in Italy [16]. All these study results show the same pattern as in our study were there was a gradual increase in seroprevalence from infancy to adolescence. But a study had done in 2008 shows very much low to the level of $11 \%$ up the age of 1 year and reaching 22 $33 \%$ by 20 years [17].

Time of primary CMV infection in general population remains elusive. Our study had a significant number of newborns who may have maternal IgG antibodies. The prevalence in newborns was $96.4 \%$ which dropped to $87.5 \%$ in 28 days to 1 year age group showing that passive transfer from mother is significant but whether it was acquired by intrauterine infection is not very clear. But still there is clear evidence to support the theory that majority of children got infected by 1 year. $[18,19,20]$. It is the same in our study where majority of children got infected during 1-5 years or 6-10 years. Increase in 6-10 years can be attributed to the fact that children in our set up goes to big schools by this age group and all most $100 \%$ of them attend schools in this age group leading to more peer exposure.

The high prevalence in these age groups revealed that congenital, cervico-vaginal, breast feeding are the major roots of acquiring infection infants. Children become infected on contact with peer group. Those who become infected often shed CMV in urine and saliva for a year or more and are thought to be the leading source of for primary CMV infection in women of reproductive age. This leads to horizontal transfer of the virus in the peer group and also the mother get primary infection in later pregnancies due to close contact with infected children. Studies have shown that CMV IgG, IgM , IgG avidity 
antibody profiles correlated with CMV shedding in urine [21]. The overall seroprevalence of CMV IgG among children 1 to 5years old in the United States was $20.7 \%$.6 But in our study it is $86.2 \%$ which also shows more chance for infection in mother during pregnancy.

Seroprevalence of CMV in young women of child bearing age is $40-80 \%$ and $90-100 \%$ in developed and developing countries respectively [22]. The Women who acquire primary CMV infection during their pregnancies have a substantial risk of delivering infants with congenital CMV disease. CMV infection of women of reproductive age cannot be prevented by immunization at present.

There is not much increase in adolescence in our part of country; the reason can be attributed to less sexual exposure and less physical contact with peer group due to cultural practices. Age group above 15years in this study was not given much importance as the frequency of 2 would have altered the result.

There was no significant difference in IgG seroprevalence between males and females. Our study also showed no significant difference with sex, and residence whether rural or urban.

With such high prevalence Of CMV in the population and with the handicap of not knowing the time of primary viremia it is prudent to provide CMV screened, leuko- depleted blood transfusions especially in premature infants, transplant recipients, and HIV patients are at high risk for acquiring serious CMV diseases.

\section{Conclusion}

The overall risk of CMV infection among adults exposed to children in a given home is difficult to predict, however it is impractical and costly to screen children routinely for CMV excretion. Till the time we have a suitable vaccine, we recommend that CMV serologic status to be evaluated in women of reproductive age who care for young children and intend to become pregnant. They should be counseled regarding the mechanisms of CMV transmission and their risks of acquiring CMV from the children in their care. Leuco-depleted blood transfusions are advised for immunosuppressed individuals.

In India the increase in prevalence in 5-16 years age group is not tha significant reason being less sexual exposure among adolescents. Because of high CMV related squealae, all newborns should be properly examined especially for auditory and ocular complications.

\section{Funding: Nil, Conflict of interest: Nil Permission from IRB: Yes}

\section{References}

1. Dollard SC, Grosse SD, Ross DS. 2007. New estimates of the prevalence of neurological and sensory sequelae and mortality associated with congenital cytomegalovirus infection. Rev Med Virol 17:355-363. http://dx.doi.org/10.1002/rmv.544

2. Stagno S, Reynolds DW, Pass RF, Alford CA. 1980. Breast milk and the risk of cytomegalovirus infection. N Engl J Med 302:1073-1076. http://dxoi.org/10. 1056/ NEJM198005083021908.

3. Pass RFHutto CLyon MDCloud G Increased rate of cytomegalovirus infection among day care center workers. Pediatr Infect Dis J. 1990;9465- 470.

4. Staras SA, Flanders WD, Dollard SC, Pass RF, McGowan JE, Jr, CannonMJ. 2008. Cytomegalovirus seroprevalence and childhood sources of infection:A population-based study among pre-adolescents in the United States. JClinVirol 43:266-271. http://dx.doi. org /10. 1016/j.jcv.2008.07.012

5. Bate SL, Dollard SC, Cannon MJ. 2010. Cytomegalovirus seroprevalence in the United States: the national health and nutrition examination surveys, 1988-2004. Clin Infect Dis 50:1439-1447. http: //dx.doi.org/10.1086/652438.

6. Lanzieri TM, Kruszon-Moran D, Amin MM, Bialek SR, Cannon MJ,Carroll MD, Dollard SC. 2015. Seroprevalence of cytomegalovirus among children 1 to 5 years of age in the United States from the National Health and Nutrition Examination Survey of 2011 to 2012. Clin Vaccine Immunol 22:245-247.

7. Engman ML, Malm G, Engstrom L, Petersson K, Karltorp E, Tear Fahnehjelm K, Uhlen I, Guthenberg C, Lewensohn-Fuchs I. Congenital CMV infection: prevalence in newborns and the impact onhearing deficit. Scand J Infect Dis. 2008;40 (11-12):935-42. doi: $10.1080 / 00365540802308431$.

8. Allovirus reactivation following hematopoietic stem cell transplantation. Sharma SK, Kumar S,Agrawal N, 
Singh L, Mukherjee A, SethetT et al J Infect Dev Ctries 2013; 7(12):1003-1007. doi:10.3855/jidc.2947.

9. van Burik JA, Lawatsch EJ, DeFor TE, Weisdorf DJ. Cytomegalovirus enteritis among hematopoietic stem cell transplant recipients. Biol Blood Marrow Transplant. 2001;7:674-679.

10. Machado CM, Dulley FL, Boas LS, Castelli JB, Macedo MC, Silva RL, Pallota R, Saboya RS, Pannuti CS (2000) CMV pneumonia in allogeneic BMT recipients undergoing early treatment of preemptive ganciclovir therapy. Bone Marrow Transplant 26: $413-$ 417. 13

11. Dollard SC, KeyserlingH,Radford K, Amin MM,Stowell J,Winter J. Cytomegalovirus viral and antibody correlates in young children. BMC Research Notes 2014, 7:776 http://www. biomedcentral. com/ $1756-0500 / 7 / 776$.

12. Kothari A, Ramachandran VG, Gupta P, Singh B, Talwar V (2002) Seroprevalence of cytomegalovirus among voluntary blood donors in Delhi, India. J Health PopulNutr 20: 348- 351.

13. Kumar H, Gupta PK, Kumar S, Sarkar RS (2008) Isseroprevalance of anti-IGM CMV among blood donors relevant in India? Indian J Pathol Microbiol 51: 351-352.

14.Mostafavi SN, Ataei B, Nokhodian Z, Yaran M, Babak A, Salehi A, et al. Seroprevalence of Cytomegalovirus infection and estimate of congenital Cytomegalovirus infection in Isfahan state, Iran: A population based study. Pak J Med Sci 2013;29 (1) Suppl:418-422.doi:http:/dx.doi.org/10.12669/pjms.291 (Suppl).354.
15.Hamkar R, Azarian B, Saadatmand Z, Nouruzbabaie,Z, Eslamlu F, Mokhtari T. Seroepidemiologic study of cytomegalovirus in under 45 years old people in orumie. Iranian J Infect Dis Trop Med. 2005;10(31):29-33.

16.de Mattia D, Stroffolini T, Arista S, Pistoia D, Giammanco A, Maggio $M$ et al. Prevalence of cytomegalovirus infection in Italy.Epidemiol Infect. 1991 Oct;107(2):421-7.

17.WilmsI R, Best AIM, Adler SP.CMV infections among African-Americans as com- Cytomegalovirus Infections among African-Americans BMC Infectious D.iseases 2008, 8:107 doi:10.1186/14712334-8-107

18. Huang LM, Lee CY, Chang MH, Wang JD, Hsu CY: Primary infections of Epstein-Barr virus, cytomegalovirus, and human herpesvirus-6. Arch Dis Child 1993, 68(3):408-411.

19. Kaye S, Miles D, Antoine P, Burny W, Ojuola B, Kaye $\mathrm{P}$ et al .Virological and immunological correlates of mother-to-child ransmission of cytomegalovirus in the Gambia. J Infect Dis 2008, 197(9):1307-13.

20. Chen et al. Kinetics of IgG antibody to cytomegalovirus (CMV) after birth and seroprevalence of anti-CMV IgG in Chinese children. Virology Journal 2012 9:304.

21. Dollard et al. Cytomegalovirus viral and antibody correlates in young children. BMC Research Notes 2014 7:776.

22. Gaytant MA, Steegers EA, Semmekrot BA, Merkus HM, Galama JM: Congenital cytomegalovirus infection: review of the epidemiology and outcome. Obstet GynecolSurv 2002, 57(4):245-256.

\section{How to cite this article?}

Kamalammal R, Balaji, Mohamed Sait Y. Age stratified Seroprevalence of Cytomegalo virus in children. Int J Pediatr Res.2016;3(5):351-355.doi:10.17511/ijpr.2016.i05.14 